\title{
Clinical Study on the Effect of Moringa oleifera on Serum Level of Glucose and Tryglyceride in Subjects Taken Tenofovir, Lamivudine and Efavirenz Combination Regimen
}

\author{
Joseph Opeyemi Tosin, \\ Obianime A. Wolfe, \\ Siminialaye M. Iyeopu,
}

Department of Pharmacology, Faculty of Basic Medical Sciences, University of Port Harcourt, Rivers State, Nigeria

Joseph Oyepata Simeon,

Department of Pharmacology, Faculty of Pharmaceutical Sciences, Bingham University, Nasarawa, Nigeria

Anuanwu Chinwe, Department of Pharmacology, Faculty of Basic Medical Sciences, University of Port Harcourt, Rivers State, Nigeria

Musa Tabitha Lubo, Department of Pharmacognosy, Faculty of Pharmacy, Gombe State University, Gombe State, Nigeria

Doi:10.19044/esj.2019.v15n21p280 URL:http://dx.doi.org/10.19044/esj.2019.v15n21p280

Abstract

Introduction/ Aim: Acquired immune deficiency syndrome (AIDS) is a disorder caused by human immune-deficiency virus. There are various life-long regimens that are currently used by HIV Patients to suppress and manage this disease. Tenofovir/Lamivudine/efavirenz (300/300/600mg) is one of the most available combinations that are frequently prescribed and dispensed to HIV patients. The aim of this clinical study is to evaluate the potential benefits of taking Moringa oleifera with Tenofovir/Lamivudine/efavirenz (TLE) on blood glucose and triglyceride level. Method: The study was designed as a Longitudinal Randomized Comparative Trial (LRCT) involving 140 HIV adult subjects (56 males, 84 females) who have been on TLE combination for at least 6 months. They were recruited from a Teaching Hospital in Nigeria. On visit 0 , blood samples of the subjects were taken for analysis. Moringa oleifera capsules (200mg) were administered by the subjects to be used beginning from the day of visit 0 , through visit 1 (after four weeks) and 2 (after 12 weeks). Blood samples of 
subjects were collected at each visit (visit 1 and 2) and analyzed for glucose and triglyceride level. Result: The analysis of each visits were compared and it was observed that there was no significant reduction in blood glucose level $(\mathrm{P}<0.01)$ of subjects in visit 1 compared to visit 0 . There was significant improvement in blood glucose level $(\mathrm{P}<0.01)$ in visit 2 compared to visit 0 , when subjects received tenofovir/Lamivudine/Efavirenz (TLE) combination without Moringa oleifera. It was also observed that there was no significant difference in the blood triglyceride level $(\mathrm{P}<0.01)$ of subjects in visit 1 and visit 2, compared to visit 0 . Conclusion: Results from the study revealed that Moringa oleifera may be useful in improving blood level of glucose of patients administering TLE combination with no observable effects on triglyceride level of HIV patients on the drug regimen.

Keywords: Moringa oleifera, Blood, Glucose, Tenofovir, Triglyceride

\section{Introduction}

There was sudden rise of Kaposi Sarcoma in 1981, observed among young homosexuals (CDC, 1982) with infrequent lung Pneumocystis Carinii Pneumonia (PCP) discovered among homosexual men and drug abusers in that same period (Masur et al., 1981; Gallo et al., 1984) The initiator for these conditions was "Acquired Immunodeficiency Syndrome (AIDS)" which was the "terminal stage infection" by a retrovirus called the Human Immunodeficiency Virus (HIV) (NIH, 2010; Leone et al., 2015). HIV is of two types namely; HIV 1 and HIV 2. They are two different viruses. HIV 1 accounts for $95 \%$ of all infectious cases worldwide. HIV 2 is mainly seen in a few West African countries. Though HIV 2 progresses slowly than HIV 1 some antiretrovirals such as nevirapine and efavirens do not work against HIV 2. The management of HIV/AIDS normally includes the use of multiple antiretroviral drugs in an attempt to control HIV infection. Antiretroviral formulations blocks HIV at certain stages of the viral "life cycle"(Estrella, Mantaring and David, 2000). Antiretroviral therapy treats HIV by suppressing the virus activity in the body. For most people who take them, these medications are very effective at keeping HIV under control. Treatment helps to improve quality of life, and it can ensure that a person with HIV has a similar life expectancy to a person without the virus. Suppressing viral activity results in a low viral load and a reduced risk of developing other illnesses. According to the United States Department of Health and Human Services (HHS), the main goal of antiretroviral therapy is to reduce a person's viral load to undetectable levels. The drugs can have serious side-effects which can lead to harm as well as keep patients from taking their medications regularly. This effects include lactic acidosis, liver steatosis, peripheral neuropathy, myopathy, lipoatrophylipodystrophy, 
elevated triglycerides and elevated risk of heart attack. Moringa oleifera Lam (Moringaceae) is a highly valued plant, distributed in many countries of the tropics and subtropics. It has an impressive range of medicinal uses with high nutritional value. Different parts of this plant contain a profile of important minerals, and are a good source of protein, vitamins, beta-carotene, amino acids and various phenolics. The Moringa leaf are prepared for consumption either fresh, dried, or as extract of an aqueous solution (Siddhuraju and Becker, 2003; Chukwuebuka, 2015; Von Maydell,1986). Some populations consume it in their daily diet, whereas others use as a nutritional supplement and for medicinal purposes, mainly for diabetes. Common ailments such as malaria, typhoid fever, swellings, cuts, hypertension and diabetes are treated with the leaves (Siddhuraju and Becker, 2003). They are also used to bring about milk production in lactating women (Olsen, 1987; Calza, Manfredi, Chiodo, 2004b; Calza,, Manfredi, Chiodo, 2004a), sediment impurities of water (Anwar et al., 2007), detoxifies the system of free radicals (Ete et al., 2004; Kumar and Mandapaka, 2013), improves immunity (to manage HIV/AIDS and treat related symptoms). The aim of this study is to evaluate the clinical effect of taking Moringa oleifera with Tenofovir/Lamivudine/efavirenz (300/300/600mg) (TLE) regimen on blood glucose and triglyceride level.

\section{Materials and Method}

The study designed was a Longitudinal "Randomized Comparative Trial" (LRCT) as applicable in clinical investigation involving two or more patient treatment groups, over a time frame. This study is designed in line with a part of the FDA (Food and Drug Administration)/WHO Phases during "randomized controlled clinical trials" (RCCT) of drugs. However, details about the application of RCCT have been clarified by FDA/WHO which made the purpose of such investigation explicit; stating that it was designed to affirm and or set aside hypothetical clinical claims (Junod and Beaver, 2013) of administrable substances. Groups were analyzed in 3 phases as baseline (commencement) 4weeks follow-up and 12 weeks post commencement of supplements (conclusion of administration).

\section{Recruitment procedure}

Subjects were recruited at the out-patient department of a Teaching Hospital HIV-clinic. Prospective participants were officially and properly informed prior to the exercise, doubts were cleared and benefits x-rayed to the patients. The Longitudinal Randomized Comparative Trial (LRCT) was employed and used. 


\section{Procedure}

The study was designed as a Longitudinal Randomized Comparative Trial (LRCT) involving a total of 140 HIV adult subjects (56 males, 84 females) who have been on TLE combination for at least 6 months. Subjects were categorized into groups as underweight, normal weight, over weight and obese. On visit 0 , blood samples of the subjects already on TLE regimen (without moringa or any supplements) for at least 6 month were taken for analysis. Moringa oleifera capsules (200mg) were given to each subject to be taken from commencement (baseline) to 12 weeks post commencement of study. Blood samples of subjects were collected at each visit (visit 1 and 2) and analyzed for glucose and triglyceride level.

\section{Data collection}

Anthropometric parameters (weight and height) and blood samples were determined for eligible patients (participants) distributed into the various categories; after duly signed consent forms were retrieved. Blood samples were analyzed at the UPTH Hematology research lab within the hospital premises.

\section{Blood Sample}

Analysis of samples was done at the hematology laboratory of the "University of Port Harcourt Teaching Hospital" (UPTH), Rivers state, Nigeria. "Computerized clinical chemistry analyzer" (VS10) (Vitro Scient) operating with the principle guided by "Beer-lambert's law" was used to determine concentration of biochemical parameters under study. Parameters as analysed were;

1. Triglyceride (TG; $0.9-1.03 \mathrm{mmol} / \mathrm{l}) ; 1000 \mathrm{ul}$ of reagent as well as $10 \mathrm{ul}$ of serum were incubated for four (4) minutes at room temperature, at a wavelength of 460-540nm.

2. Random Plasma Glucose (RPG; 4.4-7.8 mmol/l): Determined using a glucometer. The routine screening processes were undertaken by the physician.

\section{Data analysis}

Data was presented in tables using SPSS (IBM® version 23) and MATLAB (version 17). Descriptive statistics was used to express variable characteristics (with continuous data stated as mean (S.D) while categorical data as frequency [\%]). Dunnette T3 Post Hoc test of multiple comparisons was used to compare means, while binary logistic regression was used to predict factors contributing to the changes in variables. Variable interactions were tested at $95 \%$ confidence level; with $\mathrm{P} \leq 0.05$ taken to be significant. 


\section{Ethical consideration}

\section{Ethical approval}

Ethical approval was granted by the "University of Port Harcourt Research Ethics Committee"referenced as UPH/R\&D/REC/---

Patient consent

In line with the ethical requirement documented by Didia (2008), the following ethical issues were considered while carrying out the study:

i. Beneficence, (the duty to do good, and with due consideration of the best interests of the subjects).

ii. Non-maleficence, (the obligation of avoidance of harm to the subjects; when possible).

iii. Respect for persons, (Giving the deserved respect to all subjects).

iv. Justice and confidentiality (ensure fairness and unconditional privacy protection)

Individual who did not want to participate were not compelled nor forced.

Volunteer subjects gave informed consent prior to the experiment. This was done following the Revised "Council for International Organization of Medical Sciences (CIOMS) International Ethical Guidelines, Utrecht, Netherlands, June 2016". However, all relevant statutory requirements were followed to the later and where necessary.

\section{Result}

\section{Glucose and triglyceride level of ART subject taking TLE on visit day 0}

Underweight subjects were found to be 6 subjects, normal weight were 76 subjects, overweight were 44 subjects while obese were found to be 14 subjects (table 1).

\section{Effect of Moringa oleifera on ART patient taking TLE on visit day 1}

There was significant differences $(P<0.001)$ observed in mean values between TLE/Moringa (visit 1) and TLE/Non Moringa (visit 1) in the level of serum glucose of the subjects. Also, there was no significant difference between TLE/Moringa (visit 1) and TLE/Non Moringa (visit 1) in the level of serum triglyceride of the subjects (table 2,3,4 and 5)

\section{Effect of Moringa oleifera on ART patient taking TLE on visit day 2}

The differences observed in mean values between TLE/Moringa (visit 2 ) and TLE/Non Moringa (visit 0$)$ were statistically significant $(P<0.001)$ for the subjects used, while there was no significant differences $(P<0.001)$ between TDF/Moringa (visit 2) and TDF/Non Moringa (visit 0) in the level of serum triglyceride (table 2, 3, 4 and 6). 
Table 1: The descriptive characteristics and test of mean differences of glucose and triglyceride level of the HIV patients on tenofovir based ART at Visit 0 (Baseline)

\begin{tabular}{llllllll}
\hline & \multicolumn{5}{c}{ Descriptive statistics } & \multicolumn{4}{c}{ T-test of mean difference } \\
PARAMETERS & Sex & $\mathrm{N}$ & Mean \pm S.D & S.E & t-value & P-value & Inf \\
\hline \multirow{2}{*}{ GLU (mmol/l) $)$} & Male & 56 & $7.86 \pm 2.35$ & 0.31 & \multirow{2}{*}{3.010} & 0.003 & $S$ \\
& Female & 84 & $6.74 \pm 2.00$ & 0.21 & & & \\
& Total & 140 & $7.18 \pm 2.21$ & & & & \\
TG (mmol/l) & Male & 56 & $1.43 \pm 0.49$ & 0.07 & 2.305 & & \\
& & & & & & &
\end{tabular}

Table 2:Post Hoc (Dunnette T3) multiple comparison of the metabolic profile of HIV male patients on TLE taking moringa supplement across the various visits

\begin{tabular}{|c|c|c|c|c|c|c|c|}
\hline \multirow{2}{*}{ Parameters } & \multirow{2}{*}{ Visits } & \multirow{2}{*}{ Mean \pm S.D } & \multirow{2}{*}{ Min } & \multirow{2}{*}{$\operatorname{Max}$} & \multirow{2}{*}{ S.E } & \multicolumn{2}{|c|}{ 95\% C.I for Mean } \\
\hline & & & & & & $\begin{array}{l}\text { Lower } \\
\text { Bound }\end{array}$ & $\begin{array}{l}\text { Upper } \\
\text { Bound }\end{array}$ \\
\hline \multirow{4}{*}{ GLU (mmol/l) } & Visit 0 & $7.86 \pm 2.35^{* \wedge}$ & 4.22 & 18.00 & 0.31 & 7.23 & 8.49 \\
\hline & Visit 1 & $6.20 \pm 1.031$ & 4.10 & 8.71 & 0.14 & 5.92 & 6.47 \\
\hline & Visit 2 & $5.59 \pm 0.80$ & 4.08 & 8.05 & 0.11 & 5.38 & 5.81 \\
\hline & Total & $6.55 \pm 1.82$ & 4.08 & 18.00 & 0.14 & 6.27 & 6.83 \\
\hline \multirow{4}{*}{ T.G (mmol/l) } & Visit 0 & $1.43 \pm 0.49 * \wedge$ & 0.58 & 2.83 & 0.07 & 1.30 & 1.56 \\
\hline & Visit 1 & $1.25 \pm 0.40^{\prime}$ & 0.42 & 2.17 & 0.05 & 1.14 & 1.35 \\
\hline & Visit 2 & $1.09 \pm 0.55$ & 0.02 & 3.25 & 0.07 & 0.94 & 1.23 \\
\hline & Total & $1.26 \pm 0.50$ & 0.02 & 3.25 & 0.04 & 1.18 & 1.33 \\
\hline
\end{tabular}

Note: GLU=Serum glucose, TG=Triglyceride,TLE/M= Tenofovir/Lamivudine/efavirenz with moringa, $T D F / N M=$ Tenofovir/Lamivudine/efavirenz without moringa

S.D=Standard deviation, S.E=Standard error of mean, Min=Minimum, Max=Maximum,

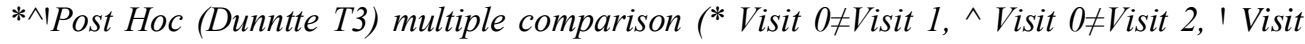
$1 \neq$ Visit $\left.2 ;{ }^{* \wedge 1} P<0.05\right)$.

Table 3:Post Hoc (Dunnette T3) multiple comparison of the metabolic profile of HIV (female) patients on TLE taking moringa supplement across the various visits

\begin{tabular}{|c|c|c|c|c|c|c|c|}
\hline \multirow[b]{2}{*}{ Parameters } & \multirow[b]{2}{*}{ Visits } & \multirow[b]{2}{*}{ Mean \pm S.D } & \multirow[b]{2}{*}{ Min } & \multirow[b]{2}{*}{ Max } & \multirow[b]{2}{*}{ S.E } & \multicolumn{2}{|c|}{ 95\% C.I for Mean } \\
\hline & & & & & & $\begin{array}{l}\text { Lower } \\
\text { Bound }\end{array}$ & $\begin{array}{l}\text { Upper } \\
\text { Bound }\end{array}$ \\
\hline \multirow{4}{*}{ GLU (mmol/l) } & Visit 0 & $6.74 \pm 2.00 * \wedge$ & 4.09 & 13.30 & 0.22 & 6.31 & 7.18 \\
\hline & Visit 1 & $6.09 \pm 1.35$ & 3.99 & 11.80 & 0.15 & 5.80 & 6.38 \\
\hline & Visit 2 & $6.06 \pm 0.73$ & 5.01 & 8.25 & 0.08 & 5.90 & 6.22 \\
\hline & Total & $6.30 \pm 1.48$ & 3.99 & 13.30 & 0.09 & 6.11 & 6.48 \\
\hline
\end{tabular}




$\begin{array}{llllllll} & \text { Visit 0 } & 1.24 \pm 0.47 & 0.30 & 2.30 & 0.05 & 1.14 & 1.35 \\ \text { T.G (mmol/l) } & \text { Visit 1 } & 1.27 \pm 0.37 & 0.24 & 2.21 & 0.04 & 1.19 & 1.35 \\ & \text { Visit 2 } & 1.15 \pm 0.47 & 0.23 & 3.18 & 0.05 & 1.05 & 1.25 \\ & \text { Total } & \mathbf{1 . 2 2} \pm \mathbf{0 . 4 4} & \mathbf{0 . 2 3} & \mathbf{3 . 1 8} & \mathbf{0 . 0 3} & \mathbf{1 . 1 7} & \mathbf{1 . 2 8}\end{array}$

Table 4: The descriptive characteristics of metabolic profile of the HIV patients on tenofovir with Moringa (TLE/M) and tenofovir not on Moringa (TLE/NM) at Visit 0 (Baseline)

\begin{tabular}{llll}
\hline GROUPS & & $\begin{array}{l}\text { GLU } \\
(\mathrm{mmol} / \mathrm{l})\end{array}$ & $\begin{array}{l}\text { T.G } \\
(\mathrm{mmol} / \mathrm{l})\end{array}$ \\
\hline & Mean \pm S.D & $7.86 \pm 2.35$ & $1.43 \pm 0.49$ \\
TLE/M & S.E & 0.31 & 0.07 \\
$(\mathrm{~N}=56)$ & Min & 4.22 & 0.58 \\
& Max & 18 & 2.83 \\
& Mean \pm S.D & $6.74 \pm 2.00$ & $1.24 \pm 0.47$ \\
TLE/FM & S.E & 0.22 & 0.05 \\
$(\mathrm{~N}=84)$ & Min & 4.09 & 0.3 \\
& Max & 13.3 & 2.3 \\
& Mean \pm S.D & $7.19 \pm 2.21$ & $1.32 \pm 0.48$ \\
Total & S.E & 0.19 & 0.04 \\
$(\mathrm{~N}=140)$ & Min & 4.09 & 0.3 \\
& Max & 18 & 2.83 \\
\hline
\end{tabular}

Table 5: The descriptive characteristics of metabolic profile of the HIV patients on tenofovir with Moringa (TLE/M) and tenofovir alone (TLE/NM) at Visit 1 (4 weeks of administration)

\begin{tabular}{llll}
\hline GROUPS & & $\begin{array}{l}\text { GLU } \\
(\mathrm{mmol} / \mathrm{l})\end{array}$ & $\begin{array}{l}\text { T.G } \\
(\mathrm{mmol} / \mathrm{l})\end{array}$ \\
\hline $\begin{array}{l}\text { TLE/M } \\
(\mathrm{N}=56)\end{array}$ & Mean \pm S.D & $6.20 \pm 1.03$ & $1.25 \pm 0.40$ \\
& S.E & 0.14 & 0.05 \\
& Range (Min-Max) & $4.1-8.71$ & $0.42-2.17$ \\
& & & \\
TLE/FM & Mean \pm S.D & $6.09 \pm 1.35$ & $1.27 \pm 0.37$ \\
$(=84)$ & S.E & 0.15 & 0.04 \\
& Range (Min-Max) & $3.99-11.8$ & $0.24-2.21$ \\
& Mean \pm S.D & $6.13 \pm 1.23$ & $1.26 \pm 0.38$ \\
& S.E & 0.1 & 0.03 \\
Total & Range(Min-Max) & $3.99-11.8$ & $0.24-2.21$ \\
$(\mathrm{~N}=140)$ & & &
\end{tabular}


Table 6: The descriptive characteristics of metabolic profile of the HIV patients on tenofovir with Monringa (TLE/M) and tenofovir alone (TDF/NM) at Visit 2 (12 weeks of administration)

\begin{tabular}{llll}
\hline GROUPS & & $\begin{array}{l}\text { GLU } \\
(\mathrm{mmol} / \mathrm{l})\end{array}$ & $\begin{array}{l}\text { T.G } \\
(\mathrm{mmol} / \mathrm{l})\end{array}$ \\
\hline & Mean \pm S.D & $5.59 \pm 0.11$ & $1.09 \pm 0.55$ \\
TLE/M & S.E & 0.11 & 0.07 \\
$(\mathrm{~N}=56)$ & Range $($ Min - Max $)$ & $4.08-8.05$ & $0.02-3.25$ \\
& & & \\
& Mean \pm S.D & $6.06 \pm 0.73$ & $1.15 \pm 0.47$ \\
TLE/FM & S.E & 0.10 & 0.05 \\
$(\mathrm{~N}=84)$ & Range $($ Min-Max $)$ & $4.18-8.25$ & $0.23-3.18$ \\
& & & \\
& Mean \pm S.D & $5.87 \pm 0.79$ & $1.13 \pm 0.50$ \\
Total & S.E & 0.07 & 0.04 \\
$(\mathrm{~N}=140)$ & Range(Min - Max $)$ & $4.08-8.25$ & $0.02-3.25$
\end{tabular}

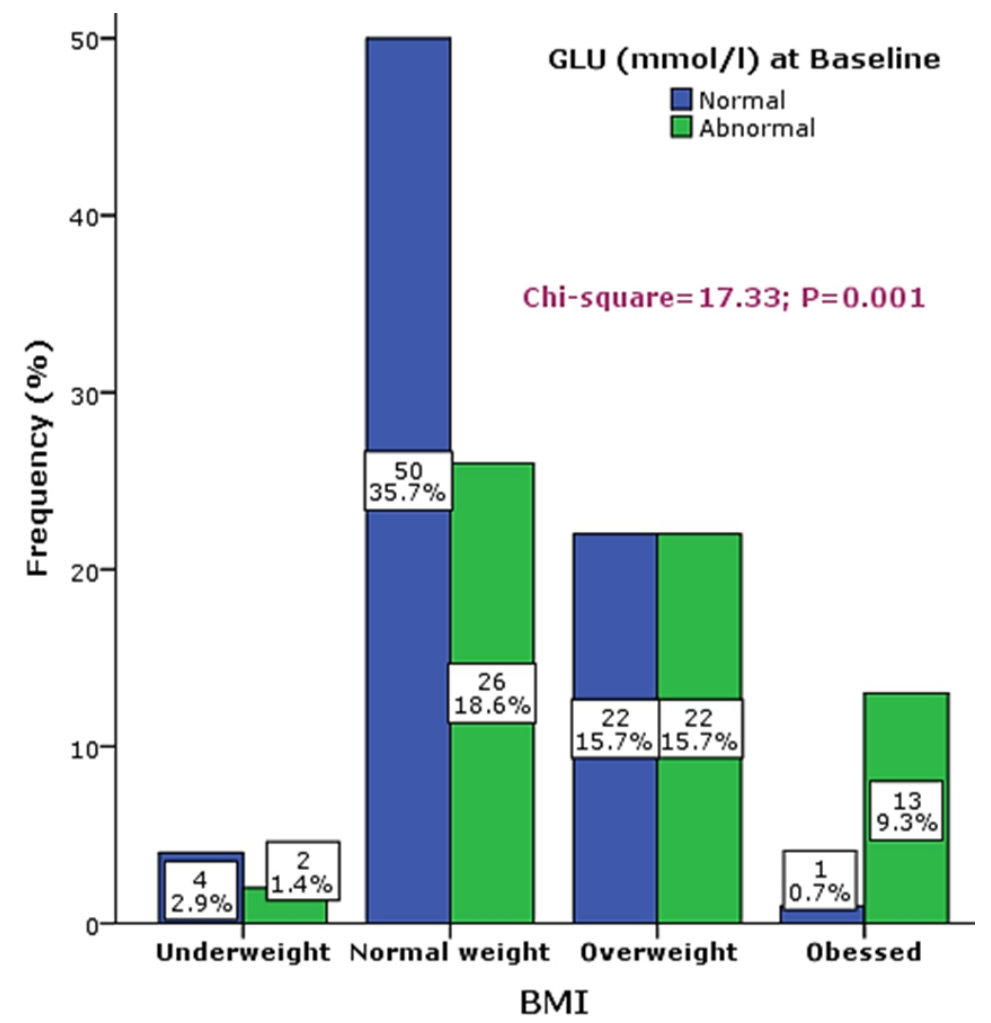

Figure 4.2: BMI associated glucose classification and distribution at Visit 0 (Baseline) 


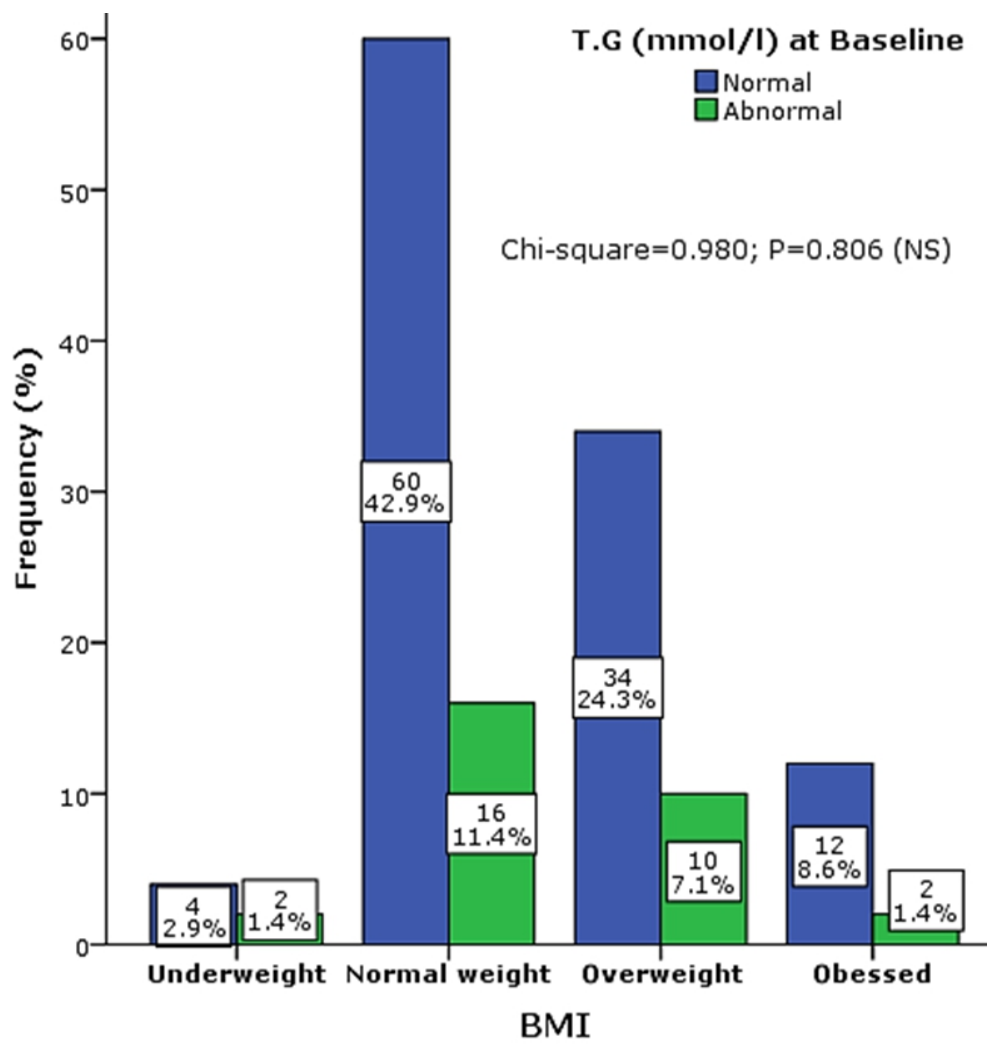

Figure : BMI associated triglyceride classification and distribution at Visit 0 (Baseline)

\section{Discussion}

Although the study was abinitio designed to investigate the effect of M. oleifera supplementation on TLE dependent HIV patients. However, various reports of ARV therapy associated metabolic abnormalities (Kar, Choudhary, and Bandyopadhyay, 2003; Meraiyebu, Ogunwole, and Izuchukwu, 2014; Ndong, Uehara, Katsumata, and Suzuki, 2007) informed this investigation. Also the increased prevalence of these abnormalities necessitated the evaluation of the relationship TDF based regimen has with abnormal presentation of selected metabolic profile. It should be known that HIV patients in the current study have been on TDF ART for at least six months and there are strong suggestions that the type of ARV-T, duration and application is significantly associated with "the severity of metabolic syndromes" (Mbikay, 2012; Moore and Chaisson, 1999; Eisinger, Dieffenbach and Fauci, 2019; Fauci and Folkers, 2012)). Moringa has been reported to have antioxidant and immune boosting effects (Deeks, Lewin and Havlir, 2013; Walensky et al., 2013).

Blood glucose level difference was mostly affected by the Moringa at Visit 2 (12 weeks after administration) with values and proportion of the 
subjects being closer to normal when compared to the baseline data. Studies have suggested that Moringa contains niazirin (=4- $(\alpha-\mathrm{L}-$ rhamnopyranosyl) phenylacetonitrile, niazicin (=methyl N-\{4-[(4'-O-acetyl- $\alpha-\mathrm{L}-$ rhamnopyranosyl) benzyl $]\}$ thiocarbamate, methyl $\mathrm{N}-\{4-\quad[(\alpha-$ Lrhamnopyranosyl) benzyl] $\}$ carbamate, and methyl N-\{4-[(4'-O-acetyl- $\alpha$ Lrhamnopyranosyl) benzyl] \} carbamate (Horn, 2012; Priyanka et al., 2015; Beardsley, 1998; Thompson et al., 2012) and the combination of the compound at specific yield values at $100 \mathrm{ppm}$ can significantly stimulated insulin release which increase glucose uptake and significantly reduce the free glucose molecules in circulation (Beardsley, 1998; Thompson et al., 2012). The time and effect on M.oleifera on ART dependent HIV patients may differ owing to the counteracting effect of both HIV and the ART on the progresses action of Moringa; However, Kar et al. (2012) and Meraiyebu et al. (2005) established that after a week administration of single doses of Moringa leaves extract in increased dosage $\left(250,300,400 \mathrm{mg} \cdot \mathrm{kg}^{-1} \mathrm{BW}\right)$ there was $1 / 2$ reduction in glucose level diabetic rats. Using rat models (Meraiyebu et al. 2005; Austin, Hokanson, Edwards, 1998; Sarwar et al 2007; Hulley, Rosenman, Bawol, Brand, 1980) also established that in normoglycaemic conditions Moringa activities may not be quite noticeable when compared glucose uptake compromised rats. The reason for such activities have been associated with certain compounds like isothiocyanates found in Moringa decreases the effect on insulin resistance and hepatic gluconeogenesis. Also Phenolic acids and flavanoids, have been reported to induce glucose homeostasis by affecting on some cellular signaling pathways in tissues known to undertake gluconeogenesis (Consensus Conference, 1984; NIH, 1983).

The study showed there was no significant reduction in the level of triglyceride in visit 1 and 2 when compared to parameter measured in visit 0 . A long-standing association exists between elevated triglyceride levels and cardiovascular disease (CVD) (Carroll et al., 2005). Hypertriglyceridemia that result from either increased production or decreased catabolism of triglyceride-rich lipoproteins (TRLs; ie, chylomicrons and very low-density lipoproteins) directly influences LDL and HDL composition and metabolism and artherogenicity (Flegal, Carroll, Ogden, Johnson, 2002; Oyepata, Jude and Opeyemi, 2018; Daniels et al 2005; Johnson et al., 2009; NCEP, 2001). Increase level of triglyceride possibly induced by taking tenofovir, lamivudine and efivarenz drugs was not reduced or controlled by moringa. This is an indication that moringa plant may not have effect in reducing or reversing cardiovascular effect induced by hyperglyceridenemia. 


\section{Conclusion}

Results from the study suggests that Moringa oleifera alongside other benefits, may be useful in controlling blood glucose level of patients taking tenofovir/lamivudine/efavirenz and maybe other tenofovir base regimen, but may be of little to no benefit in reducing serum level of triglyceride which is usually triggered by the use of tenofovir regime.

\section{Acknowledgement}

The authors of this work wishes to thank UNIPORT, UPTH and everyone involved in the success of this clinical research work.

\section{References:}

1. Austin MA, Hokanson JE, Edwards KL. (1998). Hypertriglyceridemia as a cardiovascular risk factor. Am J Cardiol. 81: 7B-12B. Beardsley T (1998). Coping with HIV's ethical dilemmas. Scientific American. 279(1): 106-112

2. Calza, L., Manfredi R, Chiodo F. (2004b). Lipodystrophy and lipid metabolism alterations in $\mathrm{HIV}$-infected patients receiving highly active antiretroviral therapy (HAART). Recenti Progressi in Medicina, 95(5): 265-75.

3. Calza, L., Manfredi, R., and Chiodo, F. (2004a). Dyslipidaemia associated with antiretroviral therapy in HIV-infected patients. Journal of Antimicrobial Chemotherapy, 53(1): 10-4.

4. Carroll MD, Lacher DA, Sorlie PD, Cleeman JI, Gordon DJ, Wolz M, Grundy SM, Johnson CL. (2005). Trends in serum lipids and lipoproteins of adults, 1960-2002. 294: 1773-1781.

5. Center for Disease Control (CDC). (1982). Persistent, generalized lymphadenopathy among homosexual males. Morbidity and Mortality Weekly Report, 31:249-52.

6. Chukwuebuka, E. (2015). Moringa oleifera "The Mother's Best Friend". International Journal of Nutrition and Food Sciences, 4(6): 624-630.

7. Consensus Conference: treatment of hypertriglyceridemia. JAMA. (1984). 251: 1196-1200.

8. Daniels SR, Arnett DK, Eckel RH, Gidding SS, Hayman LL, Kumanyika S, Robinson TN, Scott BJ, St Jeor S, Williams CL. (2005). Overweight in children and adolescents: pathophysiology, consequences, prevention, and treatment. 111: 1999-2012.

9. Deeks SG, Lewin SR, Havlir DV (2013). The end of AIDS: HIV infection as a chronic disease. Lancet. 382 (9903): 1525-33. 
10. Eisinger RW, Dieffenbach CW, Fauci AS (2019). "HIV Viral Load and Transmissibility of HIV Infection: Undetectable Equals Untransmittable". JAMA. 321 (5): 451-452.

11. Estrella MC., Mantaring JBV., and David, GZ. (2000). A double blind, randomised controlled trial on the use of malunggay (Moringa oleifera) for augmentation of the volume of breastmilk among nonnursing mothers of preterm infants. Philipp Journal of Pediatrics, 49: 3-6.

12. Ete T, Ranabir S, Thongam N, Ningthoujam B, Rajkumar N, and Thongam B. (2014). Metabolic abnormalities in human immunodeficiency virus patients with protease inhibitor-based therapy. Indian Journal of Sexually Transmitted Diseases, 35(2): 100103.

13. Executive Summary of The Third Report of The National Cholesterol Education Program (NCEP) Expert Panel on Detection, Evaluation, And Treatment of High Blood Cholesterol In Adults (Adult Treatment Panel III). (2001). 285: 2486-2497.

14. Fauci AS, Folkers GK (July 2012). "Toward an AIDS-free generation". JAMA. 308 (4): 343-4.

15. Flegal KM, Carroll MD, Ogden CL, Johnson CL. (2002). Prevalence and trends in obesity among US adults, 1999-2000. 288: 1723-1727.

16. Gallo, RC, Salahuddin SZ, Popovic M., Shearer GM, Kaplan M, Haynes BF. (1984). Frequent detection and isolation of cytopathic retroviruses (HTLV-III) from patients with AIDS and at risk for AIDS. Science, 224: 500-503.

17. Horn T (2012). "Activists Protest Stribild's \$28,500 Price Tag". AIDS. Meds. Retrieved 2014-04-11.

18. Hulley SB, Rosenman RH, Bawol RD, Brand RJ. (1980). Epidemiology as a guide to clinical decisions: the association between triglyceride and coronary heart disease. N Engl J Med. 302: 13831389.

19. Perk G, De Backer H and Gohlke J. (2012). "European guidelines on cardiovascular disease prevention in clinical practice," European Heart Journal, vol. 33, no. 13, pp. 1635-1701. View at Publisher.

20. Johnson RK, Appel LJ, Brands M, Howard BV, Lefevre M, Lustig RH, Sacks F, Steffen LM, Wylie-Rosett J. (2009). On behalf of American Heart Association Nutrition Committee of the Council on Nutrition, Physical Activity, and Metabolism and the Council on Epidemiology and Prevention. Dietary sugars intake and cardiovascular health: a scientific statement from the American Heart Association. 120: 10111020. 
21. Kar A, Choudhary, BK, and Bandyopadhyay NG. (2003). Comparative evaluation of hypoglycemic activity of some Indian medicinal plants in alloxan diabetic rats. Journal of Ethnopharmacology, 84:105-108.

22. Kumar, KP, and Mandapaka, RT. (2013). Effect of Moringa oleifera on blood glucose, LDL levels in types ii diabetic obese people. Innovative Journal of Medical and Health Science 3: 23 - 25.

23. LaRosa JC, Grundy SM, Waters DD. (2005). "Intensive lipid lowering with atorvastatin in patients with stable coronary disease," The New England Journal of Medicine, vol. 352, no. 14, pp. 1425-1435.

24. Leone, A., Spada, A., Battezzati, A., Schiraldi, A., Aristil, J., and Bertoli, S. (2015). Cultivation, Genetic, Ethnopharmacology, Phytochemistry and Pharmacology of Moringa oleifera Leaves: An Overview. International Journal of Molecular Sciences, 16(6): 12791835.

25. Masur, H., Michelis, MA, Greene, JB., Onorato, I., Stouwe, RA, Holzman, RS, Wormser, G., Brettman, L. (1981). An outbreak of community-acquired Pneumocystis carinii pneumonia: Initial manifestation of cellular immune dysfunction. North England Journal of Medicine, 305: 1431-1438.

26. Mbikay, M. (2012). Therapeutic Potential of Moringa oleifera Leaves in Chronic Hyperglycemia and Dyslipidemia: A Review. Frontiers in Pharmacology, 3, 24.

27. Meraiyebu, A., Ogunwole, E., and Izuchukwu, NS. (2014). Effects of Aqueous Extract of Moringa oleifera Seeds on Alloxan Induced Hyperglycemia. Basic Sciences of Medicine, 3(3): 37-42.

28. Moore RD, Chaisson RE (1999). Natural history of HIV infection in the era of combination antiretroviral therapy. AIDS. 13 (14): 193342.

29. National Institutes of Health (NIH). (2010). The relationship between the Human Immunodeficiency Virus and the Acquired Immunodeficiency Syndrome: Understanding and Cause. Health \& Research Topics. Available at http://www.niaid.nih.gov/topics/ hivaids/understanding/howhivcausesaids/pages/relationshiphivaids.as px

30. Ndong M., Uehara M., Katsumata, S., and Suzuki, K. (2007). Effects of Oral Administration of Moringa oleifera Lam on Glucose Tolerance in Goto-Kakizaki and Wistar Rats. Journal of Clinical Biochemistry and Nutrition, 40(3):229-33.

31. NIH Consensus Development Panel on Triglyceride, High-Density Lipoprotein, and Coronary Heart Disease. (1993). Consensus 
Conference: triglyceride, high-density lipoprotein, and coronary heart disease. 269: 505-510.

32. Olsen, A. (1987) Low technology water purification by bentonite clay and Moringa oleifera seed flocculation as performed in Sudanese villages. Effects on Schistosoma mansoni cercariae. Water Research, 21(5): 517-522.

33. Oyepata SJ, Jude EO, Opeyemi TJ. (2018). Hepatoprotective activity of extract of Homalium Letestui stem against carbon tetrachlorideinduced liver injury. Advanced Herbal Medicine. 3(4): 1-11.

34. Pedersen TR, Faergeman O., Kastelein JJP. (2005). "High-dose atorvastatin vs usual-dose simvastatin for secondary prevention after myocardial infarction: the IDEAL study: a randomized controlled trial," Journal of the American Medical Association, vol. 294, no. 19, pp. 2437-2445.

35. Priyanka D, Rajesh KS, VS and Pankaj J. (2015). Immunomodulatory Activity of Moringa oleifera in Albino Rats. Journal of Animal Research: v.5 n.2, p. 277-281.

36. Sarwar N, Danesh J, Eiriksdottir G, Sigurdsson G, Wareham N, Bingham S, Boekholdt SM, Khaw KT, Gudnason V. (2007). Triglycerides and the risk of coronary heart disease: 10,158 incident cases among 262,525 participants in 29 Western prospective studies. 115: 450-458.

37. Siddhuraju, P., and Becker, K. (2003). Antioxidant properties of various solvent extracts of total phenolic constituents from three different agroclimatic origins of drumstick tree (Moringa oleifera Lam.) leaves. Journal of Agricultural and Food Chemistry, 51: 21442155

38. Thompson MA, Aberg JA, Hoy JF, Telenti A, Benson C, Cahn P. (July 2012). Antiretroviral treatment of adult HIV infection: 2012 recommendations of the International Antiviral Society-USA panel. JAMA. 308

39. Von Maydell, HJ. (1986). Trees and Shrubs of Sahel, Their Characterization and Uses. Deutsche Gesellschaft fur Technische Zusammenarbeit, Germany: Eschborn, 334-337.

40. Walensky RP, Ross EL, Kumarasamy N, Wood R, Noubary F, Paltiel AD. (October 2013). "Cost-effectiveness of HIV treatment as prevention in serodiscordant couples". The New England Journal of Medicine. 369 (18): 1715-25. 